\title{
LAS TRES CARAS DE CHRISTINE \\ (JOHN CARPENTER, 1983)
}

\author{
Santiago García Ochoa \\ IES Manuel Chamoso Lamas
}

\section{RESUMEN}

El presente artículo explora el carácter sarcástico y autorreflexivo de Christine, adaptación de la novela homónima de Stephen King menospreciada por la crítica especializada, a partir del análisis de las tres facetas de las que se dota al personaje protagonista, un coche modelo Plymouth Fury del 58 llamado Christine: asesina en serie a la manera del Michael Myers de Halloween, mujer monstruo que condensa toda la tradición misógina occidental y corruptora de adolescentes en la que se encarna la contracultura de los 50.

PAlabras Clave: automóvil, mujer monstruo, adolescentes, cultura norteamericana, slasher.

\author{
THE THREE FACES OF CHRISTINE \\ (JOHN CARPENTER, 1983)
}

\section{Abstract}

This article explores the sarcastic and self-reflexive nature of the film Christine, based on Stephen King's homonymous novel, underestimated by specialized critical writing. This nature becomes clearly visible trough the analysis of the three facets of the leading character, a 1958 Plymouth Fury called Christine: serial killer in the manner of Michael Myers (Halloween), monster woman who condenses the entire Western misogynistic tradition and corrupting of teenagers as a continuation of the 50 s counterculture.

KEYwords: automobile, monster woman, teenagers, American culture, slasher. 


\section{INTRODUCCIÓN}

Los coches están por todas partes y tienen protagonismo en casi todos los momentos, importantes o no, de nuestra vida. Casi todo el mundo conduce y tiene al menos un coche. El vehículo motorizado es sin duda uno de los objetos de la sobrenaturaleza creada por el ser humano que más han modificado su forma de vida durante la segunda mitad del siglo xx. Actualmente asistimos a una inaplazable transición que seguramente implicará la desaparición del sistema del automóvil tal y como lo hemos conocido, pero ésa es otra historia. John Urry considera seis facetas de la automovilidad (automobility) cuya combinación dio lugar a un sistema que ha ejercido un tipo específico de dominación: producto industrial por antonomasia, objeto privilegiado de la sociedad de consumo, centro de una compleja red de interrelaciones tecnológicas y sociales (gasolineras, autopistas, moteles, talleres, etc.), forma predominante de transporte, causa más importante del deterioro medioambiental y «cultura dominante» de la vida bien organizada que desencadena potentes imágenes y símbolos literarios, presentes en las obras de autores como E.M. Foster, Scott Fitzgerald, John Steinbeck, Daphne du Maurier o J.G. Ballard (aunque Urry no lo menciona Stephen King podría cerrar perfectamente esta lista) ${ }^{1}$.

El estudio de la presencia del automóvil en las diferentes manifestaciones culturales (arte, literatura, cine) resulta de innegable interés para comprender lo que verdaderamente representa este objeto tecnológico. Yo mismo he dedicado parte de mis investigaciones a reflexionar sobre los diversos significados del coche en las películas de Carlos Saura partiendo de la iconología panofskyana y del concepto foucaultiano de heterotopía ${ }^{2}$, entendiendo el automóvil como un objeto cambiante ${ }^{3}$, generador de múltiples valores simbólicos relacionados con aspectos esenciales de la naturaleza humana, como la atracción sexual (identificación automóvil-mujer por la publicidad, celo con el que muchos varones cuidan a sus vehículos), la protección (identificación con nuestro propio hogar e incluso con el seno materno), el poder (proyección fálica y narcisista del «yo» masculino) o la muerte (capacidad destructora, accidentes de carretera como nueva y moderna forma de morir $)^{4}$.

${ }^{1}$ Urry, John (2004): «The System of Automobility», Theory, Culture \& Society, vol. 21, nums. 4-5, pp. 25-26.

2 Foucault hizo pública su teoría sobre las heterotopías en el Cercle d'Etudes Architecturales de París el 14 de marzo de 1967 (conferencia titulada "Des espaces autres»). Cfr. Foucault, Michel (1994): «Espacios diferentes», en Foucault, Michel: Estética, ética y hermenéutica. Obras esenciales, vol. III, Barcelona, Paidós, pp. 431-441. Cfr. García OchOA, Santiago (2008): «El coche como metáfora de la relación de pareja en el cine de Carlos Saura», De Arte, núm. 7, 2008, pp. 193-198.

${ }^{3}$ El coche tiene la capacidad de yuxtaponer espacios distintos: casa, dormitorio, burdel, sala de música, etc., está ligado a los periodos de tiempo como si fuese una especie de «máquina del tiempo», es inestable («un pedazo flotante de espacio, un lugar sin lugar», como dice Foucault del barco) y se opone a la concepción de «lugar» como cultura localizada en el espacio y en el tiempo. Cfr. García Ochoa, Santiago (2008), op. cit., pp. 197-198.

${ }^{4}$ Cfr. García Ochoa, Santiago (2012): "Automóvil y cine en la España desarrollista: Peppermint frappé (Carlos Saura, 1967)», Hispanic Research Journal, vol. 13, núm. 2, pp. 113-114. 
Christine es una novela original de Stephen King (1947), destacado representante del género fantástico/terror y uno de los autores más leídos y llevados al cine durante las últimas décadas del siglo xx. En 1983 se estrenaron, además de Christine, La zona muerta (The Dead Zone, David Cronenberg) y Cujo (Lewis Teague), y otras dos adaptaciones más, Ojos de fuego (Firestarter, Mark Lester, 1984) y Los chicos del maiz (Children of Corn, Fritz Kiersch, 1984) se estaban ultimando. Las historias de King se desarrollan habitualmente en entornos cotidianos donde los personajes presentan un alto grado de dependencia de las comodidades de la sociedad de consumo. Muchos críticos incluyen Christine dentro de un grupo de historias que tratan sobre la victimización de la sociedad por las máquinas, formado por los relatos The Mangler (1972), Trucks (1973) y The Word Processor of the Gods (1983), y las novelas Christine, From a Buyck 8 (2002) y Cell (2006)5. Ambientada en la pequeña ciudad universitaria de Libertyville (Pennsylvania), y con el automóvil como máquina rebelde, Christine se centra en la relación hombre/vehículo ${ }^{6}$.

John Carpenter (1948) pertenece a la generación de cineastas de los 70 que revitalizó el cine de género imprimiéndole un sello personal. Sus inicios son muy parecidos a los de Steven Spielberg, dos años mayor que él: a los ocho años ya utilizaba la cámara de $8 \mathrm{~mm}$ familiar, a los 14 rodaba cortometrajes de temática fantástica, a los 15 fundó su propia productora (Emerald Production), equipada con material técnico muy diverso, a los veinte ingresó en la School of Cinematic Arts de la USC (University of Southern California) aunque no llegó a graduarse. En 1974 dirigió su ópera prima, Dark Star, concebida inicialmente como un mediometraje, comedia de ciencia ficción que despliega un curioso sentido del humor cercano al absurdo. Su tercera película, La noche de Halloween (Halloween, 1978), rodada con tan sólo 320000 dólares de presupuesto, para la que también compuso la música y escribió el guion en colaboración con Debra Hill (productora), lo lanzó al estrellato, conquistando a crítica y público e inaugurando un nuevo subgénero del cine de terror: el slasher. En sus créditos inaugura la costumbre de preceder el título del film con su nombre: "John Carpenter's Halloween», en forma de marca autoral.

Christine le llegó a Carpenter en un momento difícil de su carrera, cuando tras el inmerecido fracaso de La cosa (The Thing, 1982), su primera película para un gran estudio (la Universal), se tambalea su acariciado deseo de encontrar un sitio en el cine comercial de Hollywood. Entonces se le presentan varios proyectos, entre ellos llevar a la pantalla la novela de Stephen King Firestarter (1980), pero ninguno prospera. Es justo en ese momento cuando acepta Christine, adaptación de otra novela de King cuyos derechos se había apresurado a adquirir el productor Richard Kobritz ${ }^{7}$ a

Cfr. Díaz Pulido, Luis Florencio (2016): Teen-Age Identity Construction in Stephen King: A Gendered View, Vitoria, Universidad del País Vasco, p. 41. En línea: http://hdl.handle. net/10810/18214.

${ }^{6}$ Stephen King retoma la figura del coche maligno en From a Buick 8: la historia de un Buick Roadmaster de 1953 cuyo propietario desapareció misteriosamente en una gasolinera en 1979 y que desde entonces descansa alojado en un cobertizo de la policía de Pennsyvania.

7 Carpenter ya había dirigido para él la TV Movie Someone’s Watching Me! (1978). 
través de su nueva compañía, Polar Film, varios meses antes de su publicación, que finalmente tendría lugar el 29 de abril de 1983, con el rodaje ya en marcha:

En cuanto lo leí supe que era uno de esos libros que, sin tener en cuenta a su autor, iba a convertirse en un best seller y, en un momento u otro, en película. Me parecía muy especial: adolescentes, chicas, rock and roll, y el amor de América por los coches convertido en una historia de terror, con la habilidad que tiene King para hacer extraños objetos familiares. Es un libro divertido, al contrario que El resplandor, que muestra la cara seria de King ${ }^{8}$.

Sin duda Kobritz pensaba que el encuentro entre dos creadores vinculados al mismo género sería un acontecimiento irresistible para los amantes del terror, y con eso consiguió convencer a la Columbia Pictures para que participase en la producción y distribuyese la película a gran escala. El guion lo escribió Bill Phillips, que condensó las casi seiscientas páginas del libro y redujo considerablemente la nómina de personajes, manteniendo sólo los principales. Como de costumbre, Carpenter se hizo cargo de la composición de la música, en este caso con Alan Howarth, su colaborador en estos menesteres desde Rescate en Nueva York (1997: Escape from New York, John Carpenter, 1981).

La película costó 10 millones de dólares. Eddie Lee Voelker (transportation coordinator) y su equipo se pasaron varios meses viajando a través de EE. UU., respondiendo a anuncios por palabras, visitando plantas de desguace y rastreando entre los vendedores de coches usados, a la busca de los automóviles necesarios para encarnar a Christine. Fue imposible localizar un número suficiente de Furys del 58 a un precio razonable, por eso se compraron también Belvederes y Savoys, dos modelos de Plymouth muy similares aunque menos exclusivos (de gama más baja) hasta llegar a veinticuatro vehículos; además, el Fury del 58 nunca se fabricó en rojo y blanco (volveremos sobre las características de este modelo más adelante). Aunque el coste de los coches fue bajo (varios eran de granjeros de Arkansas y Tennessee), posteriormente se montaron y restauraron más de quince de acuerdo con las exigencias del guion: unos debían estar relucientes, otros viejos, otros rotos y abollados, incluso se prepararon algunas mitades de coche para facilitar la filmación de varias escenas.

Christine se estrenó antes de las navidades de 1983 (9 de diciembre) con la calificación PG («Parental Guidance Suggested. Some material may not be suitable for children»), fundamentalmente por el lenguaje soez que emplean los personajes. El primer fin de semana (9-11 de diciembre) ocupó el cuarto puesto en el ranking de recaudación, con casi tres millones y medio de dólares, exhibiéndose en más de 1000 salas9. En España llegó a los cines al inicio del verano de 1984 (25 de junio) con un doblaje que mitigaba notablemente el lenguaje soez de la versión original (se calificó como "No recomendada para menores de 13 años») y un éxito

${ }^{8}$ Guillot, Eduardo (1997): King, el rey. Un universo de terror, Valencia, La Máscara, p. 54.

9 La recaudación total fue de unos 21 millones de dólares. Datos recogidos en el Box Office Mojo (IMDb). En línea: http://www.boxofficemojo.com/release/rl2672526849/weekend/. 
comercial menor (recaudación total inferior a los 73 millones de pesetas ${ }^{10}$ ). Posteriormente Christine triunfaría en el mercado del vídeo dentro y fuera de EE. UU. La recepción por parte de la crítica fue tibia, considerando de forma general que, aun estando bien resuelta, la película era impersonal, los personajes demasiado planos y/o la presencia de un coche vivo imposible de sobrellevar con solvencia ${ }^{11}$. Una de las valoraciones más entusiastas fue la de Vicente Molina Foix en las páginas de Fotogramas (septiembre de 1984):

... Christine, leída, resulta reiterativa y pretenciosa, pero en las manos de un director fogoso y algo volatinero como Carpenter es una excelente película, de hecho, la mejor que este hombre ha realizado desde Asalto a la comisaría del distrito 13 [Assault on Precinct 13, 1976]. [...] Las secuencias de persecución nocturna del vengador y las metamorfosis del vehículo tras sus fechorías se cuentan entre lo mejor del cine de horror puro (sin mixtificaciones ni coartadas) que yo he visto últimamente.

La obra de Stephen King ha suscitado un considerable interés en el ámbito académico. Christine, considerada como una de sus novelas menores, ha dado lugar a algunos trabajos de interés ${ }^{12}$. La película, en cambio, ha pasado prácticamente desapercibida $^{13}$, salvo para algunos estudiosos de las adaptaciones de King ${ }^{14}$; además,

10 Según los datos del Ministerio de Cultura y Deporte («Películas calificadas»). En línea: http://sede.mcu.gob.es/CatalogoICAA/Peliculas/Detalle?Pelicula=215984.

${ }^{11}$ Como botón de muestra se pueden ver Maslin, Janet (1983): «Christine, a Car», New York Times, December 9, p. 10; Ansen, David (1983): «Hell on Wheels», Newsweek, December 19; Ross, Philippe (1984): «Christine», La révue du cinéma, núm. 391, pp. 42-43; STRICK, Philip (1984): «Uneasy lies the head. Christine and The Dead Zone», Sight and Sound, vol. 53, núm. 2, p. 150, y Martini, Emanuela (1984): "Christine. La macchina infernale di John Carpenter», Cineforum, núm. 234, pp. 56-60.

${ }_{12}$ Entre ellos destacan Kelso, Sylvia (1996): «Take Me For a Ride in your Man-Eater: Gynophobia in Stephen King's Christine», Paradoxa, vol. 2, núm. 2, pp. 263-275 y Schopp, Andrew (1997): «From Misogyny to Homophobia and Back Again: The Play of Erotic Triangles in Stephen King's Christine», Extrapolation, vol. 38, núm. 1, pp. 66-78.

${ }^{13}$ La reciente monografía de Lee Gambin Hell Hath No Fury Like Her: The Making of Christine (Albany, Bear Manor Media, 2019), comentario secuencia a secuencia trufado con opiniones del equipo técnico y artístico, resulta un digno tributo a toda una generación de jóvenes asiduos a los videoclubs, pero carece de mayores pretensiones. En la misma línea se sitúa el libro de Andrea Denini Automobili e film nella storia del cinema americano (Recco, Le Mani, 2008), que se centra en Duel (El diablo sobre ruedas, Steven Spielberg, 1972), American Graffiti (George Lucas, 1973), Christine y Tucker: The Man and His Dream (Tucker: Un hombre y su sueño, Francis Ford Coppola, 1988), orientado a los aficionados a los coches.

${ }_{14}$ Pueden verse Madden, Edward (2007): «Cars Are Girls: Sexual Power and Sexual Panic in Stephen King's Christine», en Bloom, Harold (ed.): Stephen King, New York, Chesea House, pp. 177-192 y Simpson, Philip (2008): «The Lonesome Autoerotic Death of Arnie Cunningham in John Carpenter's Christine», en Magistrale, Tony (ed.): The Films of Stephen King: From Carrie to Secret Window, New York, Palgrave Macmillan, pp. 51-64. 
ha sido escasamente valorada en las monografías sobre Carpenter ${ }^{15}$. John Kenneth Muir, por ejemplo, ha escrito lo siguiente:

Logically and dramatically, a car as antagonist is problematic plain and simple. [...] Christine's «chase and kill» sequences are silly because the victim is always seen running right down the middle of a road, with the car in hot pursuit. It is obvious that any person, no matter how fast, cannot outrun a car on open road, so these scenes only point to the inherent ridiculousness of the situation, and the stupidity of the characters under siege ${ }^{16}$.

Christine ha sido habitualmente mal interpretada porque tiene la apariencia de una película de terror al uso, pero no funciona como tal (de ahí muchas de sus críticas negativas). En el presente artículo nos proponemos demostrar que la clave para leerla correctamente radica en valorar su carácter autorreflexivo y sarcástico, derivado de la sustitución del psicópata de turno por un coche-mujer dotado de vida propia. Podría decirse que Christine posee tres caras: la asesina en serie, la mujer monstruo y la corruptora de adolescentes, igual que la paciente del doctor Curtis Luther (Lee J. Cobb) en Las tres caras de Eva (The Three Faces of Eve, Nunnally Johnson, 1957): Eve White, Eve Black y Jane (Joanne Woodward), película sobre uno de los primeros casos de personalidad múltiple documentados.

\section{SINOPSIS ARGUMENTAL}

1957, cadena de montaje del nuevo modelo de Plymouth Fury en Detroit. Un mecánico revisa el motor del único vehículo rojo y su capó le aplasta la mano. Un trabajador negro se mete dentro a fumar; al final de la jornada aparece inexplicablemente muerto.

1978, Rockbridge (California). De la casa de un barrio residencial, sale Arnie Cunningham (Keith Gordon), el típico «novato» (nerd), que se despide de su madre Regina (Christine Belford) y se sube al coche de su amigo Dennis (John Stockwell) para ir al instituto. El primer día de clase una nueva alumna, Leigh Cabot (Alexandra Paul), causa sensación. Arnie es acosado por unos matones y Dennis le ayuda. En el trayecto de regreso Arnie ve un viejo coche rojo y queda fascinado. Un anciano, George LeBay (Roberts Blossom), les explica que se llama Christine y perteneció a su hermano, recién fallecido. Arnie lo compra por 250 dólares. En casa, la madre de Arnie se niega a tener aquel trasto, así que su hijo lo lleva al garaje-taller de Will Darnell (Robert Prosky).

Arnie, que se dedica por entero a reparar el coche, llega a un acuerdo con Darnell: a cambio de pequeños trabajos podrá utilizar las piezas que necesite. Den-

15 Tendencia alimentada por el propio director, que ha manifestado en varias ocasiones que Christine fue la primera película que realizó exclusivamente por motivos económicos.

16 Muir, John Kenneth (2000): The Films of John Carpenter, Jefferson, McFarland, p. 115. 
nis intenta ligar con Leigh sin éxito. La señora Cunningham explica a Dennis que al registrar el coche se enteró de que su anterior propietario había muerto en él. Dennis regresa a ver a LeBay, que le cuenta que su hermano se suicidó aspirando con una manguera del tubo de escape de Christine; su hija y su mujer habían muerto con anterioridad en el coche.

Christine llega al campo de fútbol americano totalmente restaurada. Arnie y Leigh salen del coche y se besan en la boca distrayendo a Dennis, capitán del equipo, que resulta gravemente lesionado. De visita en el hospital, Arnie aparece muy cambiado y se muestra sombrío; Dennis le comenta que no podrá volver a jugar al fútbol. En un autocine, Leigh está a punto de ahogarse comiendo una hamburguesa. Las puertas de Christine se bloquean y Arnie, que se encontraba en el exterior, no puede auxiliarla. Por fin Leigh consigue desbloquear el pestillo y un desconocido le practica la maniobra de Heimlich. Arnie acompaña a la chica a casa y discuten.

Los matones del instituto se cuelan de noche en el taller de Darnell y destrozan a Christine. Al descubrirlo, Arnie enloquece e insulta a Leigh. Ya en casa, después de una violenta discusión, amenaza a su padre, Michael (Robert Darnell). En el taller, Arnie le habla a Christine y el coche se autorrepara. Christine inicia ahora la caza de sus atacantes. A Moochie (Malcolm Danare) lo persigue hasta aplastarlo contra un muro. Arnie vuelve al hospital para ver a Dennis. Cuando su amigo le comenta que los matones pueden atentar de nuevo contra Christine, él asegura, enigmático, que eso no sucederá. El detective Junkins (Harry Dean Stanton) interroga a Arnie, pero no encuentra pruebas. Arnie telefonea a Leigh para reconciliarse, pero termina por encolerizarse. Las siguientes víctimas son Buddy Repperton (William Ostrander), cabecilla de la banda, y sus otros dos integrantes, Don (Stuart Charno) y Rich (Steven Tash). Christine los arrincona en una gasolinera que termina incendiándose. Buddy consigue escapar, pero Christine, en llamas, le da caza. El coche vuelve al taller donde Darnell, intrigado, se introduce en su interior. El asiento se mueve hasta asfixiarlo contra el volante. Nuevamente interviene el detective Junkins, pero el coche está intacto y Arnie tiene coartada.

Dennis sale del hospital y Leigh lo llama por teléfono: deciden eliminar a Christine. Antes, los dos amigos pasan la Nochevieja juntos; Arnie lleva a Dennis mientras bebe cerveza y conduce temerariamente. Dennis reta a Arnie y Christine grabando el mensaje en la carrocería del coche; la cita es en el taller de Darnell. Dennis y Leigh esperan en una gran excavadora, pero el coche los sorprende y persigue a la chica. En una de sus embestidas, arremete contra la oficina del taller y Arnie sale despedido atravesando el parabrisas; un cristal punzante le atraviesa el pecho causándole la muerte. Dennis aplasta a Christine hasta que sus luces se apagan y la radio enmudece. En un depósito de chatarra, Dennis, Leigh y el detective Junkins conversan frente al paquete a que ha sido reducida Christine; el amasijo mueve uno de sus hierros. 


\section{LAS TRES CARAS DE CHRISTINE}

\subsection{Christine, la ASESina EN SERie}

La adaptación de una novela al cine comporta un cambio de código que obliga a tomar importantes decisiones más allá de la mera condensación de situaciones y personajes. Se trata de lograr la máxima eficiencia dramática (y comercial) con una retórica diferente, la cinematográfica, lo cual en el caso de Christine condujo, sin duda, a eliminar los aspectos relacionados con la posesión del coche por su primer propietario, Roland LeBay (auténtica encarnación del Mal), a favor de la transformación del Plymouth Fury en una asesina en serie a la manera los de los monstruosos protagonistas de los slasher films, subgénero de terror característico de los primeros $80^{17}$.

En el ámbito académico se suelen distinguir tres grandes fases en la evolución histórica del slasher, o películas de maniacos asesinos con cuchillos u otros instrumentos punzantes en las que, como ha indicado Sánchez-Biosca, la muerte aparece convocada por partida doble:

... su primera forma es literal e icónica y se presenta, a su vez, en dos extremos, a saber, una muerte denegada -la del psicópata- y otra omnipresente -la de los personajes de la ficción-; la segunda forma es metafórica, pues representa la muerte de un relato que anuncia el agotamiento de su hálito y, en cambio, se incorpora a cada instante como animado por un fantasmal impulso que se resiste a la retirada ${ }^{18}$.

La serialidad o la iteración es pues la metonimia clave del subgénero: los asesinos matan asestando numerosas puñaladas, las víctimas se multiplican y la primera entrega siempre conoce varias secuelas, ya que el asesino nunca muere (o siempre revive).

La primera fase de la historia del slasher comprende la conformación del modelo a partir del enorme éxito de La noche de Halloween (Halloween, John Carpenter, 1978), una producción de bajo presupuesto escrita por Debra Hill y John

17 En el corto documental Christine: Ignition (Laurent Bouzereau, 2004), Phillips asegura que ésa era una buena forma de eliminar gran parte de la novela (y de no repetir cosas ya hechas), que se lo consultó a Carpenter y estuvo de acuerdo. No obstante, existe una versión mucho más compleja y edulcorada de los hechos: escribiendo el guion, a Bill Phillips le asaltó la duda sobre si la encarnación del demonio era LeBay o Christine; entonces llamó a Kobritz, que le aconsejó que hablase con Stephen King: "Gee... I never tought about that", obtuvo como respuesta; tras ver el videoclip de Bad to the Bone (George Thorogood \& The Destroyers, 1982) en la MTV, su novia Teresa le espetó: "There's your solution». Cfr. Gambin, Lee (2019): Hell Hath No Fury Like Her: The Making of Christine, Albany, Bear Manor Media, p. 9. Esta forma de presentar a Christine introduce un tono mucho menos perturbador que el de la novela de King o los propios slasher, habitualmente calificados R («Restricted. Under 17 requires accompanying parent or adult guardian»).

18 Sánchez-Biosca, Vicente (1995): Una cultura de la fragmentación. Pastiche, Relato y Cuerpo en el cine y la televisión, Valencia, Filmoteca de la Generalitat Valenciana, pp. 98-99. 
Carpenter, y Viernes 13 (Friday the 13th, Sean S. Cunningham, 1980), escrita por Victor Miller para la Paramount, que dieron lugar a la proliferación de multitud de secuelas e imitaciones, generalmente de mala calidad, de manera que a la altura de 1981 el subgénero producía ya enormes ganancias y comenzaba incluso a parodiarse en títulos como 13 asesinatos y medio (Student Bodies, Mickey Rose, 1981), Desmadre en las aulas (Pandemonium, Alfred Sole, 1982) o Reunión de clase (National Lampoon's Class Reunion, Michael Miller, 1982). Student Bodies se abre precisamente con la siguiente declaración de intenciones:

This motion picture is based on an actual incident.

Last year 26 horror films were released...

None of them lost money.

La segunda fase supone la reelaboración del slasher, agotado a la altura de 1983, en A Nightmare on Elm Street (Pesadilla en Elm Street, 1984), escrita y dirigida por Wes Craven, de la pequeña productora independiente New Line Cinema. Freddy Krueger (Robert Englund) supuso la renovación del tipo del psicópata asesino, que se vio desposeído de la existencia física de sus predecesores (sólo se aparece en los sueños de adolescentes) pero ganó la voz de la que carecían Michael Myers (Halloween) y Jason Voorhees (Friday the 13th). La curiosa iconografía del personaje favoreció la generación de merchandising en torno a su sombrero fedora marrón, su jersey a rayas verdes y rojas, su cara derretida por el calor como la superficie de una pizza y, muy especialmente, su guante terminado en afiladas cuchillas. La tercera fase consiste en la revitalización del subgénero, en pleno declive a partir de $1986^{19}$, con Scream: Vigila quién llama (Scream, Wes Craven, 1996), escrita por Kevin Williamson, dando lugar al «slasher postmoderno», caracterizado por «... an intelligent, witty, and self-conscious mode of filmmaking that deconstructed the supposedly humorless, dumb, and unselfconscious teen slashers of yesteryear ${ }^{20}$.

Los slasher poseen un tono lúdico que reclama la participación activa del espectador, pero transmiten una ideología reaccionaria compatible con las políticas de Reagan (1981-1989) que renuncia a la ambigüedad propia del género de terror de

${ }_{19}$ De las 89 películas de terror producidas en 1986, un tercio salieron directamente a vídeo: "Thus, video proved to be an amenable forum for the distribution of stigmatized cultural products». Prince, Stephen (2000): A New Pot of Gold: Hollywood under the Electronic Rainbow, 1980-1989, New York, Charles Scribner's Sons, p. 353.

${ }^{20}$ Nowell, Richard (2011): «Where nothing is off limits: genre, commercial revitalization, and the teen slasher film posters of 1982-1984", Post Script, vol. 30, núm. 2, p. 47. En un trabajo posterior Nowell distingue una cuarta etapa a partir de 2003 caracterizada por la proliferación de los remakes, en títulos como My Bloody Valentine (San Valentín Sangriento, Patrick Lussier, 2009) y Friday the 13th (Viernes 13, Marcus Nispel, 2009). Cfr. Nowell, Richard (2012): «Between Dreams and Reality: Genre Personae, Brand Elm Street, and Repackaging the American Teen Slasher Film», Iluminace, vol. 24, núm. 3, p. 72. 
los $70^{21}$. El asesino en serie del slasher es la encarnación del boogeyman («hombre del saco»), que castiga a aquellos jóvenes que consumen drogas, alcohol y tabaco, practican sexo o desobedecen a los adultos ${ }^{22}$. Para la crítica feminista, el asesino compensa su impotencia utilizando un instrumento fálico para matar y descuartizar a sus víctimas, habitualmente jovencitas sexualmente activas, con lo que, como apunta Carol Clover, el slasher naturaliza la violencia masculina y las mujeres sólo sobreviven cuando adoptan el rol del agresor masculino ${ }^{23}$. Aunque el empoderamiento de este personaje tipo, la final girl, supone la introducción de una mujer fuerte, independiente y luchadora en un contexto (la era Reagan) decididamente antifeminista ${ }^{24}$.

Christine plantea una reflexión en clave sarcástica sobre este subgénero cuando estaba siendo explotado en multitud de producciones de escasa calidad (ya han visto la luz las tres primeras entregas de Halloween y Friday the $13 t h^{25}$ ), justo antes de la renovación acometida por Wes Craven en A Nightmare on Elm Street. No en vano, Carpenter y Phillips recurren a la misma estructura de las dos películas fundacionales del slasher:

a) Prólogo ambientado en el pasado (1963 en Halloween, 1958 en Friday the 13th, 1957 en Christine) que nos ilustra sobre los inicios de la carrera criminal del psicópata.

${ }^{21}$ Espoleada por el estreno de Rosemary's Baby (La semilla del diablo, Roman Polanski, 1968) y Night of the Living Death (La noche de los muertos vivientes, George A. Romero, 1968) y la desaparición del Código Hays.

22 Como apreciaba Robin Wood a mediados de los 80: «Where the traditional horror film invited, however ambiguously, an identification with the return of the repressed, the contemporary horror film invites an identification (either sadistic or masochistic or both simultaneously) with punishment». Wood, Robin (2003): Hollywood from Vietnam to Reagan... and Beyond. Expanded and Revised Edition, New York, Columbia University Press, p. 173.

${ }^{23}$ Clover, Carol (1992): Men, Women and Chainsaws: Gender in the Modern Horror Film, Priceton, Princeton University Press, p. 226.

${ }^{24}$ Cfr. Hammer, Rhonda y Kellner, Douglas (2007): «Movies and Battles over Reaganite Conservatism", en Prince, Stephen (ed.): American Cinema of the 1980s. Themes and Variations, New Brunswick, Rutgers University Press, p. 122.

${ }^{25}$ De un lado tenemos Halloween (La noche de Halloween, John Carpenter, 1978) y Halloween II (Halloween II: Sanguinario, Rick Rosenthal, 1981), en las que Michael Myers regresa a Haddonfield (Illinois) después de escaparse del manicomio en el que había sido recluido tras matar a su hermana adolescente de niño quince años antes; Halloween III: Season of the Witch (Halloween III: El día de la bruja, Tommy Lee Wallace, 1982) nada tiene que ver con las dos anteriores (en ella un fabricante de juguetes desarrolla unas máscaras asesinas que se activan al ver uno de los auncios televisivos del producto). Del otro lado están Friday the 13th (Viernes 13, Sean S. Cunningham, 1980), en la que el supuesto asesino resulta ser la vengativa madre de Jason Voorhees, un niño discapacitado que se ahogó en el Crystal Lake en 1957, desatendido por una pareja de monitores del campamento que hacían el amor; Friday the 13th Part 2 (Viernes 13, 2." parte, Steve Miner, 1981), en la que irrumpe Jason adulto para vengar a su madre muerta a manos de la final girl en la película anterior; y Friday the 13th Part III (Viernes 13, parte III, Steve Miner, 1982), en la que Jason se pone por primera vez la máscara de hockey que se convertirá en su principal seña de identidad (se la arrebata a una de sus víctimas). 
b) Salto espaciotemporal al momento en el que se desarrollará el resto de la diégesis (1978 en Halloween, 1980 en Friday the 13th, 1978 en Christine ${ }^{26}$ ) y presentación de los personajes en un ambiente exclusivamente juvenil (campamento de verano de Crystal Lake en Friday the 13th) o en pequeñas ciudades con escaso protagonismo de los adultos (Haddonfield en Halloween y Rockbridge en Christine).

c) La irrupción del psicópata rompe la normalidad y se suceden sus impactantes asesinatos (bodycount), que hacen tambalearse, en mayor o menor medida, la causalidad narrativa.

d) Enfrentamiento final entre el psicópata y la final girl que culmina con el triunfo sobre el asesino, aunque cuando parece que éste ha sido aniquilado regresa para dar los últimos sobresaltos e incluso se llega a plantear la imposibilidad de su verdadera eliminación. En Halloween Laurie (Jamie Lee Curtis) cuenta con la ayuda de una figura masculina que además es adulta: el doctor Loomis (Donald Pleasence), psiquiatra que venía persiguiendo a Michael desde su fuga del manicomio e irrumpe en el momento justo para salvarle la vida. En Christine Leigh cuenta con la colaboración de Dennis, dotado de mucha más iniciativa que ella.

Como ha señalado Martin Rubin, un rasgo esencial de los asesinos en estas películas es su ausencia de caracterización, distanciamiento que se logra de dos maneras: manteniendo en el anonimato al asesino hasta el final de la película (adopción de la estructura whodunit para generar el suspense a partir de la novela policiaca y el cine de Hitchcock), caso de la primera entrega de Friday the 13th, o dando a conocer de entrada su identidad «... presentándolo (al igual que el tiburón de Tiburón [Jaws, Steven Spielberg, 1975]) como un ser en clave, indiferente, más animal que humano, más máquina que animal, de una fuerza más abstracta que física» ${ }^{27}$. En Christine el personaje de la asesina es una máquina que se fabrica en serie, como las sagas de los slasher. Acertadamente Rubin considera al tiburón de Jaws como una prefiguración del personaje tipo del slasher, aunque cabría recordar aquí que el escualo asesino tuvo su formulación primigenia en el sucio y destartalado camión de El diablo sobre ruedas (Duel, Steven Spielberg, 1972) ${ }^{28}$, que siguiendo con la cadena

${ }^{26}$ De las tres es la única en la que, siguiendo la novela de King, el año en el que se desarrolla la diégesis no coincide con el del estreno de la película.

${ }_{27}$ Rubin, Martin (2000): Thrillers, Madrid, Cambridge University Press, p. 202.

${ }^{28}$ La ópera prima de Spielberg se estrenó el 13 de noviembre de 1971 como una TV movie pero su enorme éxito convenció a los ejecutivos de la Universal de la idoneidad de ampliar su duración para explotarla en cines fuera de EE. UU. al año siguiente. En EE. UU. no se estrenó en pantalla grande hasta 1983 (22 de abril), unos meses antes que Christine. Si Duel puede considerarse una prefiguración de Jaws, The Car (Asesino invisible, Elliot Silverstein, 1977), también de la Universal, es una curiosa derivación en la que se presenta a un misterioso coche asesino dotado de vida propia (poseído por espíritus malignos); y entre ambas se sitúa Killdozer (Jerry London, 1974), TV movie basada en la novela corta de Theodore Sturgeon (publicada en el número de noviembre de 1944 de la mítica Astounding Science Fiction) y producida por la Universal, en la que un buldócer cobra vida 
de referentes, nos conduce hasta Hitchcock y Psycho (Psicosis, 1960), los cimientos mismos del slasher. En Christine se produce pues una reconversión del asesino en vehículo que introduce una referencia a la prehistoria del slasher ${ }^{29}$. Carpenter moviliza todos los recursos de la retórica fílmica (incluyendo la fuerza potenciadora de la música) para dotar de valor estético a la nueva forma de violencia resultante de reemplazar el arma blanca característica del slasher por un automóvil, en consonancia con su habitual rechazo de la mostración escopofílica (gratuita) de la violencia (sólo hay que comparar Halloween con Friday the 13th) y el concepto marcusiano de agresión y satisfacción tecnológica:

El fenómeno se puede describir rápidamente: el acto de agresión se lleva a cabo físicamente a través de un mecanismo altamente automatizado, mucho más poderoso que el ser humano que lo desencadena, lo mantiene en movimiento y determina su fin o destino. El caso más extremo es el del cohete; el ejemplo más corriente, el del automóvil. Esto significa que la energía, el poder activado y consumido es la energía mecánica, eléctrica o nuclear de las «cosas» más que la energía instintiva del ser humano. La agresión es, por así decirlo, transferida del sujeto al objeto, o, al menos, «mediada» por un objeto, y el blanco destruido por una cosa más que por una persona ${ }^{30}$.

Quizás el mejor ejemplo sea la escena de la persecución por la carretera de Buddy Repperton, en la que la verosimilitud se suspende en favor del mero espectáculo audiovisual (fig. 1). En cualquier caso, como ya se ha mencionado, el hecho de que la asesina sea un coche suaviza notablemente el contenido de la película, que fue calificada PG en lugar de R (como los slasher).

La presencia sobrenatural de Christine se afirma ya en el prólogo, contraviniendo una de las principales normas del relato fantástico/de terror: es necesario fijar un contexto verosímil antes de introducir el elemento fantástico, estableciéndose

tras intentar extraer un meteorito, presentada con la siguiente frase promocional que la situaba claramente a la sombra de la ópera prima de Spielberg (ambas se realizaron para la cadena $A B C$ ): «Six men... playing a deadly game of cat and mouse... With a machine that wants to kill them».

${ }_{29}$ Como han escrito Tavernier y Coursodon, aunque con tono peyorativo: «... en Christine, el camión de Duel se convierte en un coche...». TAvernier, Bertrand y Coursodon, Jean-Pierre (1997): 50 años de cine norteamericano, vol. 1, Madrid, Akal, p. 392. Stephen King siempre ha manifestado una profunda admiración por Richard Matheson, uno de los grandes maestros del género fantástico/terror, y muy especialmente por su relato Duel (que el mismo Matheson adaptó para la pequeña pantalla): «... es una de las mejores historias cortas que he leído jamás, a la altura de los clásicos de William Faulkner, Shirley Jackson y Flannery O’Connor. Está contada con la prosa característica de Matheson, que es clara, segura, austera y hermosa, de la manera en que lo son las máquinas potentes». KING, Stephen (2013): «Throtle (Acelerador). Introducción de Stephen King», en Hill, Joe; King, Stephen y Matheson, Richard, Road Rage, Modena, Panini Comics, p. 5. Para una valoración más amplia y justificada de la importancia que reviste la aportación de Matheson para Stephen King puede verse su ensayo sobre la ficción fantástica y de terror Danse macabre (New York, Everest House, 1981).

30 Marcuse, Herbert (1974): «La agresividad en la sociedad industrial avanzada», en La agresividad en la sociedad industrial avanzada y otros ensayos, Madrid, Alianza, pp. 119-120. 


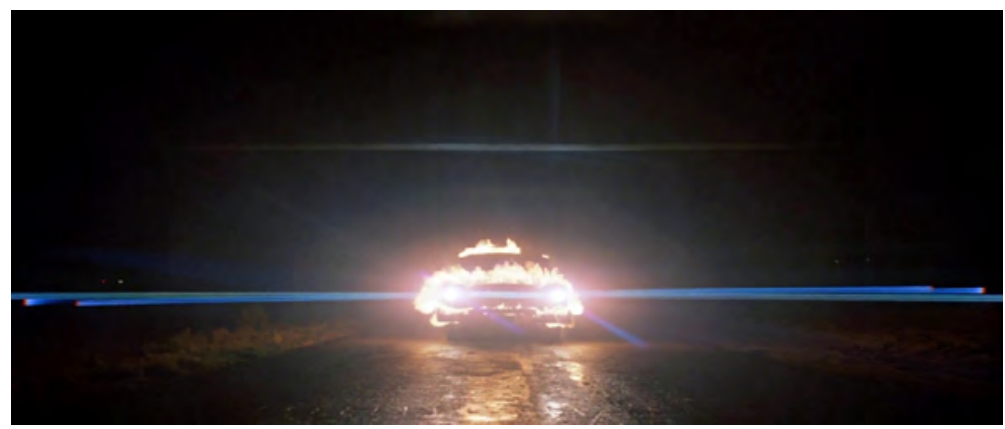

Fig. 1. Christine en llamas persiguiendo a Buddy Repperton.

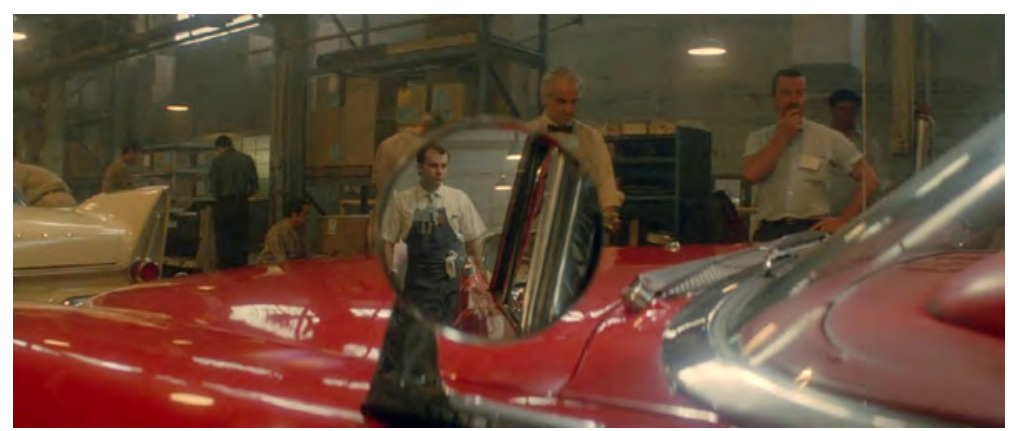

Fig. 2. Christine observa su entorno a través del espejo retrovisor.

con ello una complicidad con el espectador del cine de terror comercial, que salta de secuela en secuela, y no precisa de ponerse en situación para iniciar su disfrute ${ }^{31}$. Este prólogo contiene además un comentario sarcástico sobre «la paradoja del punto de vista» característica del slasher $^{32}$ : el plano en el que vemos reflejado a un operario en el retrovisor izquierdo del Plymouth se convierte en un plano semisubjetivo cuando descubrimos que el coche está dotado de vida propia (fig. 2) (enseguida el operario abre su capó y Christine le pilla la mano; al final de la jornada el operario

31 Precisamente la frase promocional en forma de pregunta que aparece en la parte superior del cartel original de la película (precediendo un resumen de la trayectoria de Christine) insiste en ese hecho: «How DO YOU KILL SOMETHING THAT CAN'T POSSIBLY BE ALIVE?».

32 Nos referimos a la proliferación de planos con el punto de vista del asesino, a pesar de que el espectador no sabe prácticamente nada de él, a veces incluso ni siquiera lo ha visto. En palabras de Sánchez-Biosca, a quien le debemos esa ajustada denominación: «... cuanto más cerca estamos como espectadores del psicópata, cuanto más adoptamos físicamente su punto de vista, menos sabemos de él como personaje». SÁnchez-Bıosca, Vicente (1995), op. cit., p. 102. 


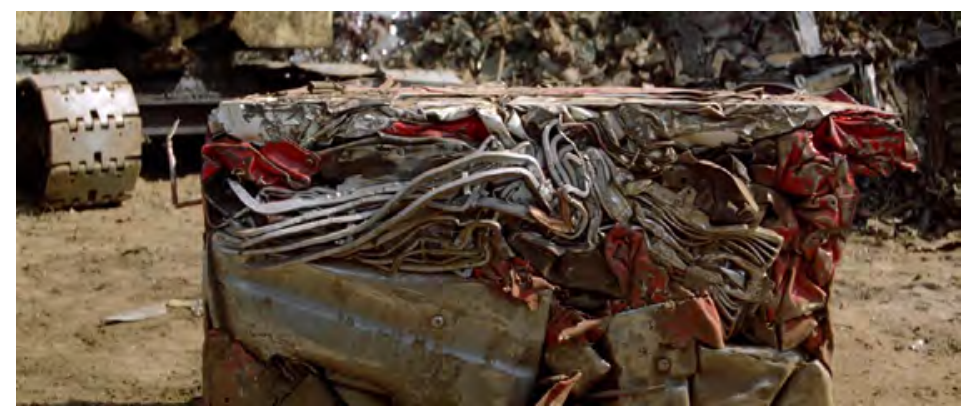

Fig. 3. Christine convertida en paquete de chatarra.

negro que fuma en su interior aparece muerto) ${ }^{33}$, funcionando a la manera de remedo burlesco del prólogo de Hallowween (1978), en el que el espectador compartía el punto de vista con el asesino para descubrir al final que se trataba de un niño ${ }^{34}$. El mismo tono lo reencontramos en el epílogo tras el clímax, aplicado en este caso a la doble denegación de la muerte (la del psicópata y la del relato) característica de los slasher. Mientras el detective Junkins, Dennis y Leigh conversan comienza a sonar Come on Let's Go (Ritchie Valens, 1959), que parece emerger del paquete de chatarra al que ha sido reducida Christine ${ }^{35}$; enseguida surge un trabajador que lleva un radiocasete, desvelándose la verdadera fuente del sonido. Leigh dice: «God, I hate rock and roll», la cámara se acerca lentamente al paquete de chatarra (fig. 3) y uno de los hierros del radiador de Christine se mueve levemente, entonces entran los primeros acordes de Bad to the Bone, canción con la que se había presentado al Plymouth en el prólogo; por corte neto se pasa a fondo negro y aparecen los créditos.

\subsection{Christine, LA MUJer MONSTRUO}

El Plymouth Fury es un automóvil característico de los 50, década en la que la industria norteamericana, capitaneada por Ford, Chevrolet y Plymouth (the low-priced three), experimentó un espectacular incremento en la venta de vehícu-

${ }^{33}$ Evidentemente ya desde un primer momento para el espectador atento y prevenido, conocedor de la novela de King o de la promoción de la película. También da pistas el acompañamiento musical extradiegético: la canción Bad to the Bone (George Thorogood \& The Destroyers, 1982); precisamente la canción es reemplazada por el grito del primer operario cuando el capó cae sobre su mano.

${ }^{34}$ Carpenter introducirá planos de punto de vista del coche, tomados como si los faros delanteros fuesen sus ojos y casi siempre en movimiento (camera car), en las secuencias de los asesinatos de la banda de Repperton y en la del enfrentamiento final en el taller de Darnell, pero nunca de forma abusiva.

35 George Thorogood y Bill Phillips aparecían adecuadamente ataviados como sus artífices en una escena que no se llegó a incluir. 
los nuevos de enormes dimensiones, renovados diseños, motores potentes y todo tipo de prestaciones. Por fin el consumidor medio podía aumentar su gratificación sensual (placer y confort) adquiriendo estos lujosos automóviles de primera mano a unos precios razonablemente bajos: «There is pleasure in gleaming paintwork, in the smell of the new seats, the thunk of a heavy door, the purr of a willing engine ${ }^{36}$.

El Fury de 1958 estaba equipado con tablero acolchado, asientos rellenos con espuma, limpiaparabrisas de velocidad variable y un sistema de suspensión exclusivo de la Chrysler Corporation (Torsion-Aire Ride) que, como se indica en un publirreportaje aparecido en la revista Life del 11 de mayo de 1959 (pp. 108-109), se basaba en el mismo principio (las barras de torsión) que el de los coches deportivos importados de entre 10000 y 15000 dólares. $\mathrm{La}$ «V» del radiador advertía de su potente motor de ocho cilindros en V y 290 caballos de potencia. El precio del Fury superaba levemente los 3000 dólares (3032), y fue el Plymouth más caro de $1958^{37}$. En la novela de Stephen King George LeBay relata que su hermano lo consiguió por 2100: «I do remember that he wrote her sticker price was just a tad under $\$ 3000$, but he "jewed em down", as he put it, to $\$ 2100$ with the trade-in. He orderer her, paid ten per cent down, and when she came, he paid the balance in cash -ten-and twenty-dollar bills» ${ }^{38}$. El Fury del 58 sólo se fabricó en Buckskin Beige con acabado dorado. Según George, Roland hizo que pintaran el suyo a su gusto: "Chrysler never offered the 1958 Plymouth Fury in those colours; Rollie had gotten it custom-painted ${ }^{39}$. Aunque de esto nada se dice en la película, se añadió la secuencia inicial de la cadena de montaje en la que Christine es el único coche rojo y blanco.

El gusto por el estilismo provocó una considerable feminización de los coches en la década de los $50^{40}$, que pasaron a decorarse como joyas, incorporando las formas aerodinámicas de los aviones a reacción y los cohetes (Jet Style), con un motivo predilecto: las aletas. No en vano la «F» de «Fury» distorsiona su forma para imitar la de un avión y se emplean los términos «jewell» y «gem» para referirse al coche en la publicidad impresa del Plymouth Fury de 1958. Baudrillard considera

36 Offer, Avner (1998): «The American Automobile Frenzy of the 1950s», en Bruland, Kristine y O'Brien, Patrick (eds.): From Family Firms to Corporate Capitalism: Essays in Business and Industrial History in Honour of Peter Mathias, Oxford, Oxford University Press, p. 323.

${ }_{37}$ Mueller, Mike (1993): Chrysler Muscle Cars, Osceola, MBI, p. 21. El término muscle car se emplea en el ámbito norteamericano para referirse a coches grandes, deportivos, con motores de gran cilindrada y precio asequible. Como adjetivo, «muscle» se puede traducir por «potente» o "poderoso», pero como sustantivo, además de «músculo», en sentido figurado quiere decir "matón». Todos estos significados del término encajan a la perfección con Christine, una de las primeras muscle cars. Este tipo de automóviles se harían muy populares en los 60.

${ }^{38}$ KING, Stephen (1992): Christine, London, Hodder and Stoughton, p. 118.

39 KING, Stephen (1992), op. cit., p. 121. King comete el error de indicar que el coche tenía cuatro puertas, cuando en realidad ese modelo tenía sólo dos: así figura en los registros de compra del coche de 1957 y 1978 (sorprendentemente los dos fechados el 1 de noviembre) que analizan Leigh y Dennis (pp. 463-464).

40 Incluso llegaron a diseñarse vehículos específicamente concebidos para uno u otro sexo: Chrysler fue la pionera con Le Comte (negro y bronce) y La Comtesse (rosa), presentados en 1954. 


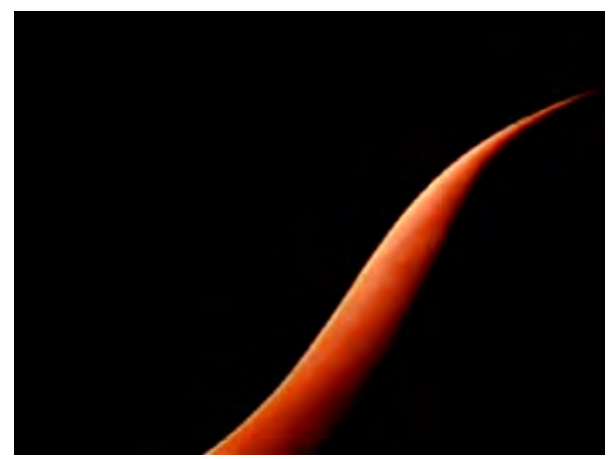

Fig. 4. Las seductoras formas de la carrocería de Christine parecen las curvas de un cuerpo de mujer en el tráiler promocional de la película.

que la incorporación de las aletas al diseño de los coches supone la transformación de la velocidad, "una función de orden fálico», en «una velocidad formal, fija, casi visualmente comestible» ${ }^{41}$. Precisamente el primer tráiler de Christine que se proyectó en salas (y que conoció una versión más corta para televisión) consistió en una lograda descripción audiovisual de Christine apoyada en el carácter femenino de su fisionomía: inicialmente observamos fugaces flashes de formas curvas envueltas en penumbra que parecen corresponderse con un cuerpo de mujer (fig. 4), mientras una voice over comenta "She is seductive, she is passionate, she is possessive»; pero poco a poco vamos identificando esas formas con las de una carrocería, justo cuando la voz dice "She is pure... evil. She is Christine, a 1958 Plymouth Fury possessed by Hell» (entonces ya vemos una rueda).

En cualquier caso el automóvil siempre ha sido un objeto de uso preferentemente masculino, con el que, desde muy pronto, el hombre estableció una estrecha relación, proyectando sobre él su personalidad, especialmente en la cultura norteamericana. Es célebre la reflexión que William Faulkner pone en boca de uno de los personajes de su novela Intruder in the Dust (1948): «The American really loves nothing but his automobile: not his wife his child nor his country nor even his bank account first $»^{42}$. Según Baudrillard «... como todo objeto funcional mecánico, el automóvil es ante todo (y para todos, hombres, mujeres, niños) vivido como falo, como objeto de manipulación, de cuidados, de fascinación» ${ }^{43}$. En un anuncio del Plymouth Fury de 1958 aparecido en la revista Motor Trend (abril de 1958, p. 59) se explica al lector que sólo este modelo le ofrece las tres «P» de la moderna conducción «in a unique blending of family car confort and the exciting capabilities of a

41 Baudrillard, Jean (1969): El sistema de los objetos, México, Siglo XXI, p. 67.

42 Faulkner, William (1948): Intruder in the Dust, New York, Random House, p. 238.

43 Baudrillard, Jean (1969), op. cit., p. 79. 
true competition car!»: Prestige, Performance, Personality; concluyendo con el siguiente eslogan: «FOR THE MAN WHO REALLY LOVES CARS». Es, decir, se le ofrece al hombre la posibilidad de que los tres atributos que le proporciona su falo (PHALLUS, Penis) puedan ahora verse sobredimensionados al proyectarlos sobre su nuevo coche (Plymouth). Pero de esta condición de objeto poseído y de manipulación del coche surge también su identificación con la mujer. Según Dorfles:

... el hombre (en este caso el varón) ve en el automóvil el equivalente libidinoso del otro sexo. El coche es, pues, la amiga, la amante, la esposa, el flirt: Coche y perro son los dos ejemplos más típicos del sometimiento total a dos "criaturas» a las que el hombre puede dedicar sus atenciones sentimentales sintiéndose totalmente dueño de ellas. Tanto para con su perro como para con su coche el hombre tiene atenciones patéticas (los lava, los lleva de paseo, los lustra, los peina, juega con ellos) que no puede tener nunca $-\mathrm{o}$ casi nunca- con sus hijos, con su mujer, con sus amigos ${ }^{44}$.

Este autor también cree que el coche es un objeto femenino por su condición de contenedor, de asilo, que se puede asimilar con el seno materno ${ }^{45}$. La otorgación del género femenino al coche lleva aparejada la incorporación de la mujer al catálogo de comodidades de la sociedad de consumo dentro de un sistema patriarcal, o lo que es lo mismo, considerar que las mujeres son objetos de uso y consumo, y no sujetos activos ${ }^{46}$.

La novela de Stephen King está plagada de pasajes en los que se asocia a Christine (y por extensión a los coches) con una mujer. A continuación repasamos algunos presentes en la película. La primera vez que ve a Christine, Arnie se refiere al coche en femenino: «She could be fixed up. She could... yeah. Oh, She could be really tough», igual que George LeBay: «She'll start [...] Start her up [...]. Her name's Christine [...]. My asshole brother bought her back in September ' 57 [...]. Brand new, she was. She had the smell of a brand new car. That's just about the finest smell in the world... except maybe for pussy». Durante su segundo encuentro, LeBay le confiesa a Dennis: «Probably the only thing my brother ever loved in his whole rotten life was that car. No shitter ever came between him and Christine. If they did, watch out». Leigh no quiere besarse dentro del coche porque lo contempla como su rival: «Because... I hate that car. You care more about that car than you care about me», y cuando Arnie le dice que se supone que las chicas tienen celos de otras chicas y no de los coches, ella le espeta: «This car's a girl».

Como adelantaba el primer tráiler que se proyectó en los cines, Christine aparece dotada de gran parte de los atributos negativos que la cultura occidental ha ido asociando con la mujer a lo largo de los siglos, cuya base se encuentra en la Antigüedad griega (como habitáculo se puede identificar con la caja de Pandora; su

${ }^{44}$ Dorfles, Gillo (1973): Sentido e insensatez en el arte de hoy, Valencia, Fernando Torres, p. 95 .

45 Dorfles, Gillo (1973), op. cit., p. 96.

46 Madden, Edward (2007), op. cit., p. 178. 


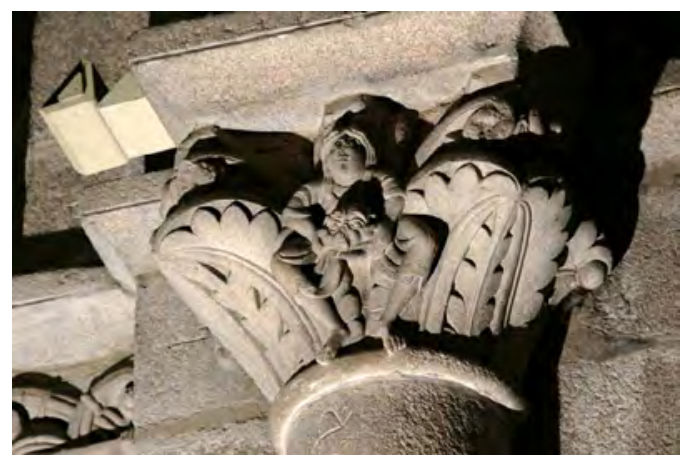

Fig. 5. Representación de la vagina dentata en un capitel de la catedral de Santiago de Compostela.

penetrante «mirada», sobre todo cuando enciende sus faros, recuerda a la de Medusa; su capacidad destructora y su poder de sometimiento emulan los de las amazonas) y la tradición judeocristiana (a partir de las figuras de Eva, la primera mujer para los cristianos, y Lilith, la primera mujer para los judíos, modelada por Dios con polvo y heces). Dentro de la iconografía cristiana medieval se pueden citar como ejemplo elocuente los relieves escultóricos de mujeres mostrando su vagina (igualmente Christine ostenta una « $\mathrm{V}$ » dorada coronando su rejilla cromada), aunque ésta a veces puede ser reemplazada por una máscara felina, como sucede en el capitel que se encuentra tras la puerta de Platerías de la catedral de Santiago de Compostela (1101-1112) (fig. 5), de acuerdo con la tradición figurativa medieval que identifica la boca del infierno con una cabeza de león, tomada del Antiguo Testamento (fundamentalmente de Job, 41) ${ }^{47}$. Moralejo considera que en este capitel se visualiza «... una metáfora implícita ya en los Proverbios y desarrollada posteriormente por san Jerónimo: la os vulvae puede ser la os inferni» que pudiera muy bien servir como advertencia sobre las prostitutas que acechaban a los peregrinos, según lo recogido en el sermón Veneranda Dies del Códice Calixtino ${ }^{48}$. Christine se abre, tras el logo

47 Cfr. Nodar Fernández, Victoriano (2019): «El bestiario esculpido en los capiteles de la catedral románica de Santiago: una aportación a las fases constructivas y al programa iconográfico del monumento" (tesis doctoral), Santiago de Compostela, Universidade de Santiago de Compostela, pp. 160-161. En línea https://minerva.usc.es/xmlui/handle/10347/20665.

48 El castigo que se propone es que se les corte la nariz, y Moralejo se pregunta si será casualidad que los únicos deterioros de este capitel coincidan con la nariz de la mujer y el morro del grotesco animal. Cfr. Moralejo, Serafín (1985): «Artistas, Patronos y Público en el Arte del Camino de Santiago», Compostellanum, vol. xxx, núms. 3-4, pp. 422-423. En la visión de la mística alemana Hildegard von Bingen la figura de la Iglesia es perturbada por la presencia de su contrario, el Anticristo, un monstruo situado entre sus piernas que luego se separa de su cuerpo, tal y como aparece representado en su primera obra, escrita entre 1141 y 1151, Scivias (fol. 214 vo. Scivias II, 11 [W]), en cuyo texto se equiparan la boca y los dientes del monstruo con los de un león. Cfr. Williams, David 
de la Columbia, con la presentación de su «V» sobre fondo negro acompañada del ruido de varios acelerones de su motor, adecuado equivalente mecánico de los rugidos de la fiera medieval.

Mucho más recientemente, cuando las grandes transformaciones del siglo XIX incrementaron el temor de los hombres sobre la capacidad de afirmación de las mujeres, se configuró la figura de la mujer fatal (femme fatale) que, como Christine, fascina, siembra la muerte a su paso y hace sucumbir a algunos hombres. La femme fatale tuvo un primer desarrollo en el arte y la literatura, pasando luego a ser explotada por el cine, fundamentalmente en dos géneros: el cine negro y el de terror.

Barbara Creed ha estudiado lo que ella denomina «the monstrous-feminine» en el cine a través de un extenso catálogo de tipos, a saber:

... the amoral primeval mother (Aliens [Aliens: El regreso, James Cameron], 1986); vampire (The Hunger [El ansia, Tony Scott], 1983); witch (Carrie [Brian De Palma], 1976); woman as monstrous womb (The Brood [Cromosoma 3, David Cronenberg], 1979); woman as bleeding wound (Dressed to Kill [Vestida para matar, Brian De Palma], 1980); woman as possessed body (The Exorcist [El exorcista, William Friedkin], 1973); the castrating mother (Psycho [Psicosis, Alfred Hitchcock], 1960); woman as beautiful but deadly killer (Basic Instinct [Instinto básico, Paul Verhoeven], 1992); aged psychopath (Whatever Happened to Baby Jane? ['Qué fue de Baby Jane?, Robert Aldrich], 1962); the monstrous girl-boy (A Reflection of Fear [Un reflejo de miedo, William A. Fraker], 1973); woman as non-human animal (Cat People [La mujer pantera, Jacques Tourneur], 1942); woman as life-in-death (Life-force [Lifeforce: Fuerza vital, Tobe Hooper], 1985); woman as the deadly femme castratrice (I Spit on Your Grave [La violencia del sexo, Meir Zarchi], 1978) ${ }^{49}$.

Christine posee cualidades de todas ellas pero con la que mejor se identifica es con la «mujer castradora», ejemplificada en la vagina dentata, imagen universal presente en relatos míticos y representaciones figurativas de los cuatro continentes (Creed repasa en el capítulo ocho de su libro los textos de Freud que invocan esta figura). En la novela de Stephen King aparecen algunas referencias explícitas a ella ${ }^{50}$. En la película hay varias implícitas: una totalmente nueva y el resto adaptadas del texto literario. La primera la localizamos en la secuencia de la cadena de montaje, cuando el capó del coche cae sobre el brazo del operario como una boca que se cie-

(1996): Deformed discourse. The function of the monster in mediaeval thought and literature, Exeter, University of Exeter Press, p. 167 y Nodar Fernández, Victoriano (2019), op. cit., p. 163. Tanto el capitel de la catedral de Santiago como la miniatura del Scivias nos remiten a la figura de la vagina dentata, a la que enseguida nos referiremos.

${ }^{49}$ Creed, Barbara (1993): The Monstrous-Feminine. Film, feminism, psychoanalysis, New York, Routledge, p. 1.

50 En el sueño de Dennis (capítulo 7 «Bad Dreams»); en su comentario sobre un amigo dominado por su novia (a la que compara con Christine): «I know they say that a stiff dick has no conscience, but I tell you now that some cunts have teeth (...)» (KING, Stephen (1992), op. cit., p. 132); y durante el enfrentamiento final, la única de estas tres referencias explícitas que se pone en imágenes en la película (a la que enseguida nos referiremos). 


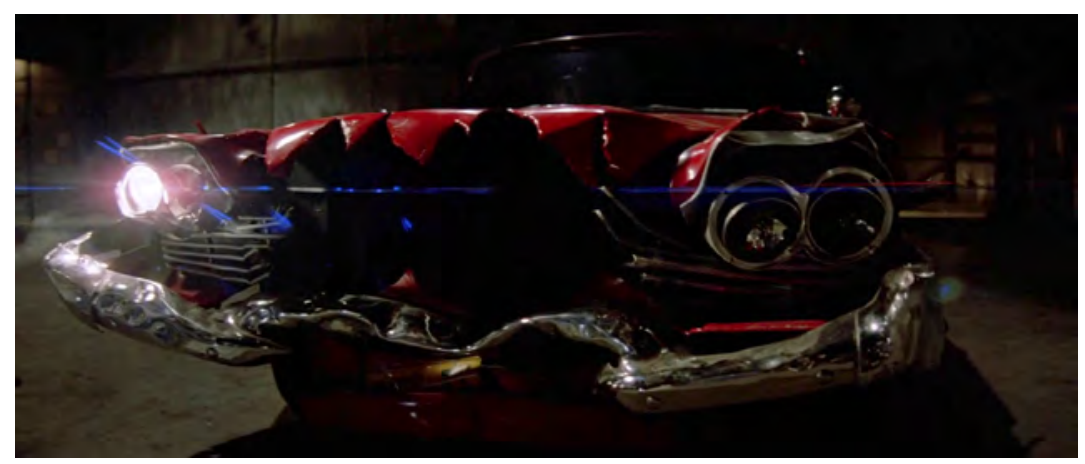

Fig. 6. Representación de la vagina dentata en Christine.

rra por meter éste la mano en un lugar prohibido (dicho de una forma más vulgar: por «meterle mano" a Christine). Este sentido de acceso prohibido y peligroso se hace extensible también al espacio interior del Plymouth Fury («útero materno» que funciona como la "gruta del infierno»), en el que encuentran la muerte el operario negro, la hija y la mujer de Roland LeBay, el propio Roland LeBay y Will Darnell; sólo Leigh consigue salvarse del atragantamiento en su interior. La referencia más clara la encontramos durante el enfrentamiento final, cuando se rompe la parte frontal del vehículo al embestir un coche y parece que Christine tiene una boca abierta con enormes dientes, como si fuese una vampira o un tiburón (fig. 6), tal y como aparece descrito en el guion de rodaje: «Christine, her hood crimped and torn from her first hit, shows bright metal through the broken paint. Her hood and grill take on the look of shark's teeth ${ }^{51}$. Curiosamente, cuando Christine embiste al coche éste se le mantiene pegado como si lo tuviese agarrado con los dientes (fig. 7) (lo mismo sucede en la secuencia del ataque a la banda de Buddy Repperton en la gasolinera). Por último también podría apuntarse que el rojo del coche es el color de la sangre que derrama Christine, pero también el del atributo abyecto más destacado de la mujer, que durante siglos le valió su asociación con el diablo: la menstruación.

El cambio introducido con respecto a la novela, la transformación de Christine en una psicópata asesina a la manera de Michael Myers, refuerza el simbolismo misógino de la mujer castradora; además, la presencia de la «violación» a cargo de

51 Phillips, Bill (1983): Christine. Shooting Script, Polar Film Corporation, p. 118. Trasposición casi textual de la novela: «Christine roared at Leigh again, her hood crimped almost double from her first hit, bright metal showing through the broken paint at the sharpest points of bend. It looked as if her hood and grille had grown shark's teeth». KING, Stephen (1992), op. cit., p. 572. Las descripciones de la novela y el guion contienen una referencia explícita a la vagina dentata, pero su equivalente audiovisual (un coche con la parte frontal rota que parece una boca con dientes puntiagudos) es una referencia implícita. 


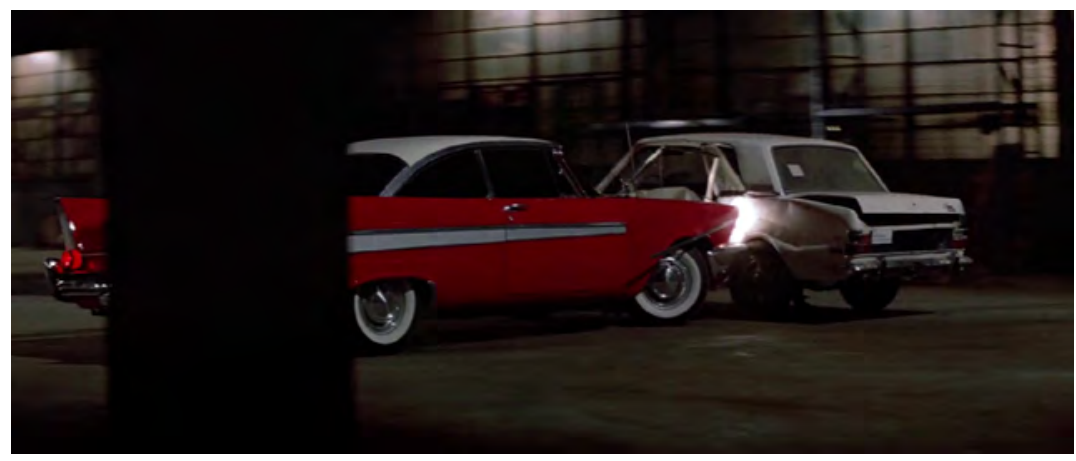

Fig. 7. Christine embiste y engancha a otro coche ¿̨con sus dientes?

la banda de Buddy Repperton y la posterior venganza permiten vincular la película con el ciclo de los rape-revenge films, que funcionó durante los 70 y 80 como uno de los mejores emblemas del feminismo combativo (Barbara Creed mencionaba I Spit on Your Grave, uno de sus grandes hitos).

La figura del psicópata asesino del slasher suele aparecer condicionada por una infancia traumática y la confusión sexual (desde su precedente más notable: el Norman Bates de Psycho), e incluso en los casos en los que estos aspectos no aparecen en primer término el asesino es frecuentemente un perturbado sexual ${ }^{52}$. Quizás por ello en algunos slasher con estructura whodunit anteriores a Christine se aprovecha este tópico para jugar con la sexualidad del psicópata y confundir al espectador, que siempre espera que el asesino sea un hombre, como sucede en la fundacional Friday the 13th. En la misma línea se sitúan Feliz Nochebuena (To All a Good Night, David Hess, 1980) ${ }^{53}$, la producción canadiense (distribuida en EE. UU. por Columbia Pictures) Cumpleaños mortal (Happy Birthday to Me, J. Lee Thompson, 1981), Sweet Sixteen (Jim Sotos, 1982) ${ }^{54}$ o Campamento sangriento (Sleepaway Camp, Robert Hiltzik, 1983) ${ }^{55}$. En Christine, sin embargo, se afirma claramente la sexua-

52 Clover, Carol J. (1987): «Her Body, Himself: Gender in the Slasher Film», Representations, núm. 20, p. 195.

53 Aquí los asesinos, que actúan disfrazados de Papá Noel, son un matrimonio sediento de venganza por la muerte de su hija dos años antes en un colegio femenino.

${ }^{54}$ En este caso la poderosa imagen del cartel ya generaba una inquietante expectativa: una mujer desnuda con los brazos cruzados sobre los pechos aparece sumergida hasta el pubis, mientras la parte inferior de su cuerpo (oculta bajo el agua) es sustituida por la hoja de un cuchillo (que parece emerger, literalmente, de su pubis, cubierto por unas braguitas negras), figurando en el lado izquierdo la siguiente frase promocional «What terrors are unleashed when a girl turns...». El film llegó a las salas unos meses antes que Christine (el 16 de septiembre de 1983).

55 Película estrenada en EE. UU. el 18 de noviembre de 1983 (veinte días antes que Christine) en la que se eleva este juego con la sexualidad al paroxismo más demencial y absoluto: desde el 
lidad femenina de la asesina desde el inicio, y ello a pesar de tratarse de un coche en lugar de un ser humano, por lo que este arquetipo del perturbado parece amoldarse mejor al personaje de Arnie Cunningham, que queda perfectamente definido en los primeros minutos de película como un novato (nerd). Dennis llega en su propio coche a casa de los Cunningham para recoger a su amigo y lo recibe su madre (Regina), que lleva el almuerzo de su hijo en la mano. A continuación sale Arnie con una bolsa de basura que se le rompe y lo mancha todo. Durante el trayecto al instituto Arnie le cuenta a Dennis cómo jugando al Scrabble su madre no le dejó poner "Fellatio» para ganar la partida, mientras éste le da consejos sobre cómo propiciar su primer encuentro sexual ${ }^{56}$. Christine domina a Arnie anulando a Regina e intenta hacer lo mismo con Leigh, su primera novia, bloqueando sus puertas cuando ella se atraganta en su interior; y con Dennis, su mejor amigo, que casi se queda inútil de cintura para abajo por detenerse a contemplar cómo Arnie se besa con Leigh (podría decirse que Christine lo eclipsa con su mirada, cual Medusa, y provoca el accidente $)^{57}$.

En el slasher eran castigados y asesinados aquellos jóvenes que no seguían los valores tradicionales (fundamentalmente las chicas promiscuas). El asesino encarnaba al «hombre del saco» (boogeyman) y los mataba con un objeto fálico y un movimiento que hacía referencia al acto sexual. Christine mata fundamentalmente hombres (en el pasado propició la muerte de la hija y la mujer de LeBay), y convierte a Arnie, el novato reprimido controlado por su madre, en su pareja y su cómplice (volveremos sobre ello más adelante). El mecánico negro y Darnell mueren en su interior, cuando entran en la "gruta del infierno». Los miembros de la banda de Buddy Repperton son embestidos. El coche ataca furioso convertido en un objeto fálico similar al cuchillo del slasher: choca contra los otros vehículos y atraviesa o les pasa por encima a sus víctimas humanas (Moochie y Buddy Repperton) ${ }^{58}$. Arnie muere tras salir despedido a través de la luna delantera y clavársele en el costado un cristal alargado, con forma de cuchillo (es el único asesinato en el que aparece la sangre) (fig. 8).

inicio se le proporcionan indicios al espectador para que sospeche de la retraída niña Angela (Felissa Rose), pero al final, en un giro sorprendente e inesperado, en lugar de cambiar la identidad de la asesina se le cambia sólo de sexo, ya que Angela resulta ser un niño.

56 Ya en el instituto, primero tiene problemas para abrir su taquilla (situación que puede leerse como una metáfora de su inexperiencia sexual); después los matones que lo acosan le quitan la bolsa del almuerzo y Buddy Repperton le dice que en ella debería figurar su nombre: «ARNIE CUNTINGHAM" (cunt es "coño» en inglés).

57 Si Dennis, capitán del equipo de fútbol americano del instituto, es el ligón de turno, Leigh representa su equivalente femenino, es guapa pero también inteligente, una final girl cuya falta de iniciativa se verá paliada por la activa colaboración del primero. Sólo actuando juntos lograrán vencer a Christine, que en la secuencia del enfrentamiento final aloja en su interior a un Arnold Cunningham totalmente poseído.

58 Las letras de la matrícula de Christine, CQB, son las siglas de «Close Quarters Battle», táctica militar en la que pequeñas unidades se enfrentan al enemigo cara a cara, luchando cuerpo a cuerpo o con armas de mano, como espadas o cuchillos. 


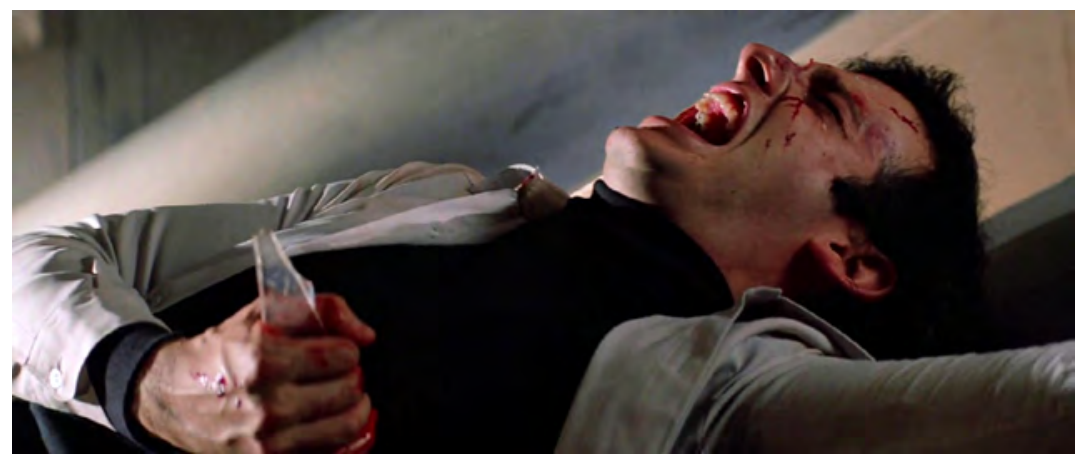

Fig. 8. La truculenta muerte de Arnie.

Christine representa el miedo y la ansiedad masculinos ante los logros del movimiento feminista, que recoloca a la mujer en la sociedad pero deja descolocado al hombre. El empleo que se hace en la película de las canciones de rock lo confirma. La letra de Bad to the Bone (George Thorogood \& The Destroyers, 1982), tema que acompaña el «nacimiento» del coche en la cadena de montaje como música extradiegética, relata en primera persona la trayectoria de un rompecorazones que embauca y hace sufrir a las mujeres desde el mismo día de su nacimiento. Pero si se la aplicamos a Christine puede funcionar en sentido inverso. Igual sucede con todas las canciones que suenan en su radio, su voz, ya que a través de los versos seleccionados estratégicamente por Bill Phillips, John Carpenter y Michael Ochs (music coordinator) el coche expresa lo que siente en cada momento (todos ellos de éxitos de rock and roll de los 50). Podemos decir entonces que Christine invierte definitivamente los roles de las canciones de rock, la música más misógina y agresiva que se ha producido, según Deborah Harding y Emily Nett ${ }^{59}$. Así, Arnie queda reducido a un mero objeto sexual que satisface sus necesidades al dedicarle Pledging my love (Johnny Ace, 1954) o I Wonder Why (Dion and The Belmonts, 1958). Este tono sarcástico se acentúa cuando sus mensajes sirven para comunicarse con sus víctimas, ya que en esos casos Christine celebra de manera especial su potencia y su superioridad. El mejor ejemplo quizás sea la forma en que llama la atención de Moochie antes de matarlo, haciendo sonar en su radio Little Bitty Pretty One (Thurston Harris, 1957):

Little bitty pretty one

Come on and talk-a to me

Lovey dovey lovey one

Come sit down on my knee

59 Harding, Deborah y Nett, Emily (1984): «Women and rock music», Atlantis, vol. 10, núm. 1, p. 60 . 


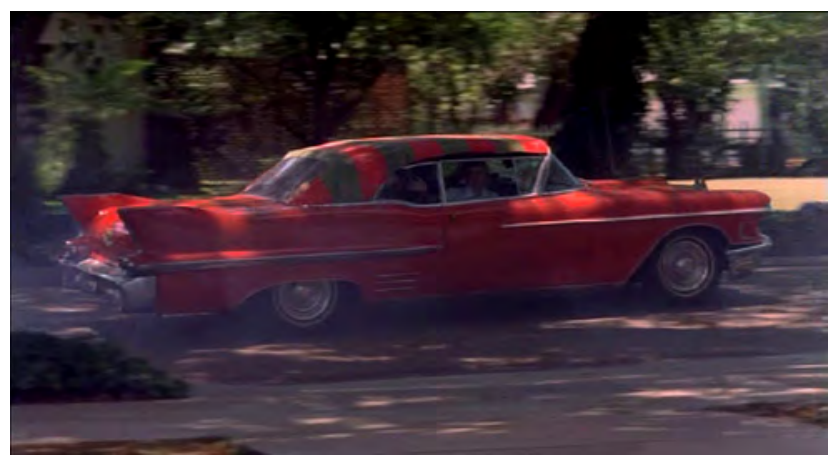

Fig. 9. El Cadillac Series 62 convertible de 1958 poseído por Freddy Krueger de A Nightmare on Elm Street.

Tell you a story

Happened long time ago

A-little bitty pretty one

I've been watchin' you grow.

Desde esta perspectiva Christine puede contemplarse como la prefiguración de Freddy Krueger, el primer monstruo asesino del slasher dotado no sólo de voz propia, sino también de un peculiar y corrosivo sentido del humor, que se irá haciendo cada vez más patente a medida que se sucedan las secuelas. Quizás no sea una casualidad que la primera entrega de la saga de A Nightmare on Elm Street, estrenada el 11 de noviembre de 1984 (casi un año después que la película de Carpenter), se cierre con la inquietante presencia de un vehículo muy parecido al Plymouth Fury, rojo y con aletas, un Cadillac Series 62 convertible de 1958 (el coche del novio de la protagonista) que cobra vida propia (está poseído por Krueger, su capota adopta los colores de su jersey) y se lleva secuestrados a los jóvenes (fig. 9).

\subsection{Christine, la corruptora de Adolescentes}

Arnold Cunningham es un joven de diecisiete años que acaba de sacarse el permiso de conducir y accede a su primer automóvil, acontecimiento trascendental en la vida de un norteamericano, ya que representa el primer paso hacia la independencia y la libertad ${ }^{60}$. Pero en Christine el acceso al primer coche se fusiona con

${ }^{60}$ Actualmente el coche está perdiendo este sentido dentro de la cultura juvenil norteamericana debido a barreras económicas y legales, pero también porque los adolescentes han encontrado un sustitutivo en la liberación virtual de las obligaciones familiares que les ofrece el smartphone: «In a sense, cruising the Internet has replaced cruising the streets. The aimless search for the chance 
la primera relación amorosa en lo que se pudiera considerar una broma macabra sobre los cuidados que los hombres les brindan a sus coches. La primera vez que Arnie ve a Christine siente un flechazo, quiere comprar el coche sea como sea (en la novela King lo especifica textualmente: «Arnie had fallen in love with a 1958 Plymouth Fury, one of the long ones with the big fins» $\left.{ }^{61}\right)$. Todavía con el Plymouth a medio reparar, se mete en su interior, se echa sobre el volante (con la boca pegada a «ella») y acaricia su salpicadero (la escena se corta justo ahí, en el inicio de la relación sexual, como suele ser frecuente en las películas) ${ }^{62}$; en la radio suena Pledging my love (Johnny Ace, 1954):

Forever my darling my love will be true

Always and forever I'll love just you

Just promise me darling your love in return

May this fire in my soul dear forever burn

My heart's at your command dear.

Después de dejar a Leigh en su casa tras el aciago episodio del autocine, Christine no se pone en marcha porque siente celos, hasta que Arnie le habla amablemente: "Come on. Come on Christine. Come on babe, please. It's all right. Everything's the same». Entonces se enciende y suena en su radio I Wonder Why (Dion and The Belmonts, 1958):

Don't know why I love you, don't know why I care

I really love, you know I love you dear

I wonder why, I love you like I do

Is it because I know you love me too.

La escena de la autorreparación del Plymouth tras ser destruido por la banda de Buddy Repperton se presenta como si se tratase de un striptease ${ }^{63}$ : Arnie se pone frente a Christine y le dice "Okay, show me», entonces se encienden sus faros, entra

encounter with hands on the wheel can be done more efficiently, safely, and cheaply with fingers on the touchscreen. Meetings, if «merely» virtual, still take place; and one can display or document onself on Facebook, Twitter, and Instagram in ways that parallel or even improve upon casual encounters and conversations from a slow-moving or parked car. And these meetings can take place whenever one wants, not just on weekend nights». Cross, Gary S. (2018): Machines of Youth. America's Car Obssession, Chicago, Chicago University Press, pp. 183-184. En el caso de Arnie, tal y como se especifica en la película y la novela, como el joven es menor de 18 años, la firma de uno de sus padres o tutores debe aparecer junto a la suya en el registro de compra para poder ser propietario de un coche.

${ }^{61}$ KING, Stephen (1992), op. cit., p. 8.

${ }^{62}$ Según Lee Gambin: «He massages her steering wheel as if he were fondling the breasts of a girlfriend, and he places his tired and exhausted head upon it the way a husband would relax with his wife after a long day at the office». Gambin, Lee (2019), op. cit., p. 113.

${ }^{63}$ Para Fabrizio Liberti: «... una sorta di strip-tease biomeccanico con tanto di ancheggiamenti mimati dal ricostruirsi della carrozzeria». LiberTi, Fabrizio (1997): John Carpenter, Milano, Il Castoro, p. 61. 


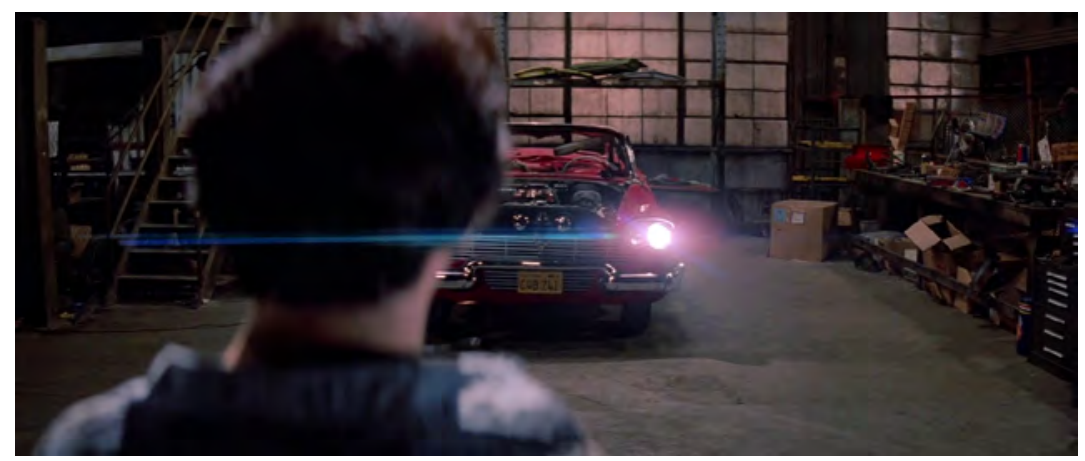

Fig. 10. Una autorreparación que parece un striptease.

una música extradiegética apropiada (el clásico instrumental Harlem Nocturne en versión de The Viscounts, 1959), y comienza la sesión (fig. 10).

El modelo del coche y la música rock que suena en su radio remiten a una generación problemática para la que el automóvil formó parte de un ritual de iniciación que llevaba asociados el sexo y la muerte. El alargamiento del periodo de formación de los jóvenes tras la II Guerra Mundial condujo a que en los 50 los adolescentes (teenagers) se convirtieran en un grupo social diferenciado con hábitos de vida y costumbres propias que giraban en torno al high school, espacio de sociabilidad que implicaba una serie de rituales relacionados con el deporte, los bailes de graduación, los cines al aire libre, el primer coche, el sexo, las nuevas canciones del rock and roll, etc., pero también con peligros como el alcohol y las drogas. Todo ello quedó plasmado en un nuevo subgénero, el de las teen movies, como Rebelde sin causa (Rebel Without a Cause, Nicholas Ray, 1955) o High School Confidential! (Jack Arnold, 1958), desarrollándose incluso modalidades que ilustraron subculturas más específicas, como las hot rod movies, que reunían a adolescentes independientes, chicas "calientes", rock and roll y, sobre todo, coches dotados de enormes y veloces motores (hot rods), en títulos como Dragstrip Girl (Edward L. Kahn, 1957) o Hot Rod Gang (Lew Landers, 1958).

El ídolo de esta generación fue James Dean, un joven inadaptado, aficionado a las carreras, que murió en un accidente de carretera el 30 de septiembre de 1955, dos horas después de haber sido multado por exceso de velocidad. El mismo año había interpretado al joven rebelde de los 50 por excelencia: Jimmy Stark, en Rebel Without a Cause. "17 years old in the year 1955 -what makes him tick... like a bomb?», anunciaba la frase promocional del cartel de la película. El comportamiento y la transformación física de Arnie, su cazadora roja, y la presencia del coche como desencadenante de la tragedia son referencias directas a Rebel Without a Cause. Su muerte violenta en el interior de Christine también se puede equiparar con la del joven actor, que tenía 24 años cuando estrelló su Porsche Spyder 550, dando lugar a toda una mitología. Como escribe Estrella de Diego: 
No obstante, la muerte moderna más codiciada se asocia con frecuencia a la velocidad, como ratifica Rebelde sin causa. La muerte moderna por excelencia debe ser espectacular, violenta, rápida, pudiendo llegar a aparecer como noticia de primera página en un periódico por lo menos local ${ }^{64}$.

Un tipo de muerte que completa la simbiosis entre hombre y máquina. La historia de amor entre Arnie y Christine concluye en «una boda entre tecnología y sexo", tal y como la planteó J.G. Ballard en su novela Crash (1973). Arnie sale despedido atravesando la luna delantera cuando Christine se lanza contra la oficina de Darnell y se le clava en el costado un trozo de cristal. Antes de expirar acaricia la parte frontal del coche, incluyendo, cómo no, la «V» ${ }^{65}$. Existe además una estrecha relación, seguramente nada casual, entre Little Bastard (el nombre que Dean le puso a su Porsche) y Christine, que parece heredar de aquél su condición de coche maldito. Tras el accidente del actor, George Barris compró los restos del Porsche para reconstruirlo, pero mientras lo colocaban en su garaje el vehículo se precipitó y cayó sobre uno de sus mecánicos, rompiéndole las dos piernas. Entonces Barris decidió despiezarlo: el motor se lo vendió al doctor Troy McHenry, un cirujano de Beverly Hills, que lo instaló en su coche y falleció al estrellarse contra un árbol en una carrera; la dirección la compró el doctor William E. Eschridu, otro cirujano, que tuvo un accidente grave en la misma carrera. El mismo Barris se encargó de reconstruir la carrocería para exhibirla en un garaje, pero al poco de instalarla allí se declaró un incendio: ardieron todos los vehículos menos el Porsche Spyder. Tiempo después George Barkuis se llevó el coche en un camión para exhibirlo en Salinas, cerca del lugar donde falleció Dean, y durante el viaje el Porsche se soltó de su sujeción y lo arrolló. En 1960 el Ayuntamiento de Miami decidió utilizar el automóvil para una campaña de seguridad en carretera. Una vez finalizada, durante el viaje de vuelta a Los Ángeles, el conductor del camión que lo transportaba paró en un bar de carretera; cuando regresó el coche ya no estaba ${ }^{66}$.

Christine, encarnación del Mal, transmite un oscuro legado: el que la contracultura de los 50 legó a las futuras generaciones norteamericanas. La presencia del prólogo que recoge el "nacimiento» del Plymouth Fury bad to the bone en Detroit en 1957, ausente en la novela, lo deja bien claro. Esta secuencia puede leerse como una

${ }^{64}$ De Diego, Estrella (1999): Tristísimo Warhol. Cadillacs, piscinas y otros simbolos modernos, Madrid, Siruela, p. 17. Rebel Without a Cause se estrenó el 29 de octubre de 1955, por lo que cuando los espectadores tuvieron ocasión de verla James Dean ya llevaba casi un mes muerto. Este suceso introdujo, en cierta manera, una reescritura de la trágica secuencia del acantilado, en la que Jimmy Stark se salva saltando de su coche en el último momento mientras a su contrincante se le engancha la cazadora en la manilla y no puede evitar caer al vacío.

${ }^{65}$ En la novela es Michael, el padre de Arnie, el que va dentro de Christine. Arnie y su madre mueren en un accidente al estrellarse el Volvo de Regina contra un remolque porque se les introduce en el vehículo el espíritu maligno de Roland LeBay, que cuando lo ve todo perdido en el taller de Darnell abandona a Christine y vuelve con Arnie. Cfr. KING, Stephen (1992), op. cit., p. 585.

${ }^{66}$ Cfr. Gasca, Luis (1994): James Dean. Cenicero de carne, Barcelona, La Máscara, pp. 191193. Y esta es sólo una versión reducida de los muchos males que se le atribuyen a Little Bastard. 


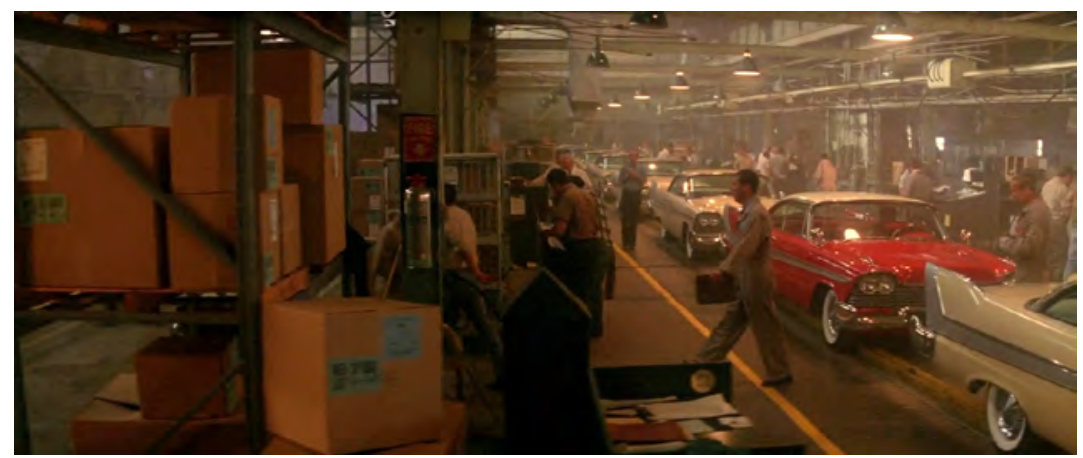

Fig. 11. Christine desentona en la cadena de montaje.

alegoría de los estragos que causó la mercantilización capitalista de la contracultura, representada por la disrupción que introduce Christine en la cadena de montaje (el establishment, el American way of life del consumo de masas) (fig. 11). La novela $O n$ the Road de Jack Kerouac, publicada precisamente en 1957, convirtió a la generación beat un fenómeno multitudinario, y para esa fecha el rock and roll también estaba ya plenamente mercantilizado. El salto espaciotemporal de 1957 a 1978 se lleva a cabo en la película recurriendo a dos versiones diferentes de la popular canción Not Fade Away, aunque la presencia previa de Bad to the Bone (George Thorogood \& The Destroyers, 1982) empleada como música extradiegética introduce una especie de prolepsis sonora que adelanta la perpetuación del legado del rock. El tema que suena en la radio de Christine cuando se cobra su primera víctima es la primera versión de Not Fade Away (Buddy Holly y Norman Petty, 1957), mientras que en la radio del coche de Dennis suena la versión de Tanya Tucker (1978), del mismo año en el que se desarrolla la diégesis ${ }^{67}$. La película se cierra, recordémoslo, con otra sucesión de canciones, Come on Let's Go (Ritchie Valens, 1959) en la radio del trabajador del cementerio de automóviles ${ }^{68}$ y nuevamente Bad to the Bone como

${ }^{67}$ Nótese que el título de la canción quiere decir «No desaparece», y que el término fade se emplea en inglés en el argot cinematográfico para referirse al fundido. Carpenter pasa de un tiempo a otro por corte neto. Por último, la canción prosigue en 1978 justo en el mismo punto en que se quedó en la radio de Christine en 1957, aunque, eso sí, con un cambio de ritmo considerable y la sustitución de la voz masculina por otra femenina, que simbólicamente nos dice: «A love for real not fade away».

${ }^{68}$ Los versos que se escuchan son:

Oh, well, I love you, babe

And I'll never let you go

Come on, baby.

Curiosamente en el guion de rodaje de la película la canción que escuchaba el trabajador del cementerio de coches era Bad to the Bone, lo cual introducía un anacronismo: el tema de George Thorogood 
música extradiegética, que reafirman la permanencia del legado del rock $^{69}$, separadas por la declaración ultraconservadora de Leigh: «God, I hate rock and roll».

La herencia negativa de la contracultura se identifica en Christine con algunos de los grandes problemas sociales del primer mandato de Reagan (1981-1984). Las lesiones provocadas por los accidentes de tráfico eran la primera causa de muerte en jóvenes blancos de entre 15 y 19 ańos $^{70}$. El consumo de drogas, sobre todo de alcohol, aparecía además como su principal desencadenante. Ambos problemas fueron eficazmente combatidos a lo largo del periodo desde la administración local, estatal y federal, espoleadas por asociaciones ciudadanas como MADD (Mothers Against Drunk Drivers) y RID (Remove Intoxicated Drivers), que luchaban desde el convencimiento de que la conducción bajo los efectos del alcohol era un acto criminal muy grave que debía ser castigado más severamente, presentándolo como un drama de buenos y malos ("the killer drunk and his victims») para movilizar a la opinión pública ${ }^{71}$. En su discurso de Año Nuevo de 1983, el presidente Reagan pedía a toda la nación que se involucrase en desterrar a los conductores borrachos «... off our roads and get them off now», que habían causado 25000 muertes y 650000 heridos graves el año anterior, extrayendo la siguiente conclusión: «The drunk driver has turned his car into a weapon, a weapon that threatens the lives and safety of the innocent ${ }^{72}$. El 14 de marzo de ese mismo año la cadena NBC estrenó la $T V$ movie titulada MADD: Mothers Against Drunk Drivers (William A. Graham, 1983), que recreaba la lucha de la «madre coraje» Candy Lightner para mover al gobierno y la justicia a cambiar las leyes tras la trágica muerte de su hija de trece años, atropellada por un conductor borracho. Según los datos manejados por McCarthy, el punto más alto de la cobertura mediática (prensa y televisión) de la conducción bajo los efectos del alcohol se alcanzó precisamente en el periodo 1983-1984 ${ }^{73}$.

Existe una secuencia especialmente interesante desde este punto de vista en Christine. Se trata del viaje de casa de Dennis a casa de Arnie, donde los dos amigos van a pasar la Noche Vieja juntos. Arnie conduce a toda velocidad mientras bebe cerveza, brinda, tira la lata por la ventanilla y suelta el volante (fig. 12). Dennis le

es de 1982 y la diégesis se desarrolla en 1978 (además de que en ese caso no surgiría la confusión, ya que la radio de Christine sólo reproducía éxitos de los 50). Cfr. Phillips, Bill (1983), op. cit., p. 126.

${ }^{69}$ La última canción que Christine hace sonar en su radio, mientras está siendo aplastada por la excavadora que conduce Dennis, es Rock and Roll Is Here to Stay (Danny \& the Juniors, 1958).

${ }^{70}$ Fingerhut, Lois A. y Kleinman, Joel C. (1989): «Mortality among Children and Youth", American Journal of Public Health, vol. 79, núm. 7, p. 901.

${ }^{71}$ Cfr. Gusfield, Joseph (1988): «The Control of Drinking-Driving in the United States: A Period in Transition?», en Laurence, Michael D., Snortum, John R. y Zimring, Franklin E. (eds.): Social Control of the Drinking Driver, Chicago, University Press, pp. 124-125.

72 AP (1983): "President calls for curbs on drunken driving», The New York Times, January 2, p. 16.

${ }_{73}$ Cfr. McCarthy, John (1994): «Activistas autoridades y medios de comunicación: el movimiento contra la conducción de automóviles bajo los efectos del alcohol», en Gusfield, Joseph y Laraña, Enrique (coords.): Los nuevos movimientos sociales: de la ideología a la identidad, Madrid, Centro de Investigaciones Sociológicas, pp. 339-340. 


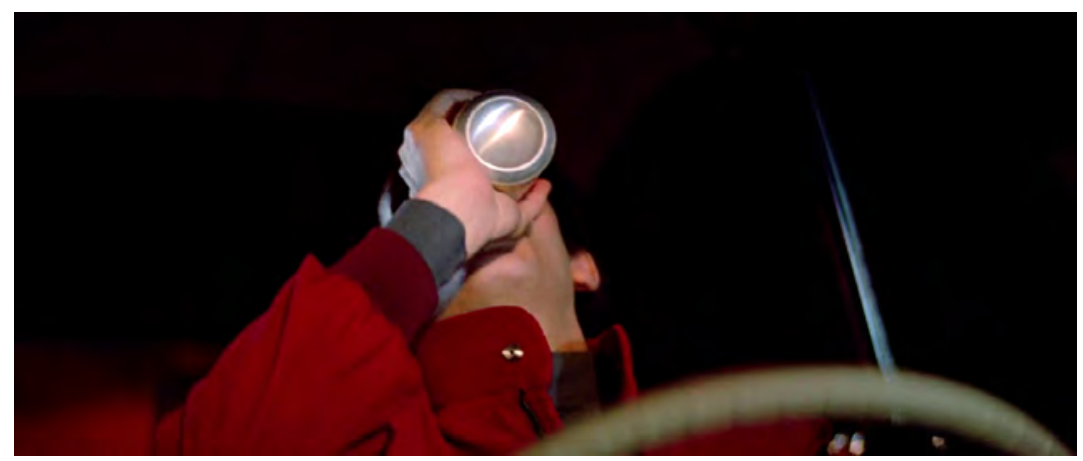

Fig. 12. Arnie bebe cerveza mientras conduce.

confiesa que está preocupado por su actitud, y Arnie le dice que siempre serán amigos mientras él esté de su parte, porque ya sabe lo que le pasa a los que no lo hacen... Luego le habla apasionadamente acerca del amor:

Let me tell you a little something about love, Dennis. It has a voracious appetite. It eats everything: friendship, family. It kills me how much it eats. But I'll tell you something else. You feed it right, and it can be a beautiful thing, and that's what we have. When someone belives in you you can do anything. Any fucking thing in the entire universe. And when you belive in that someone, then watch out, world, because nobody can stop you. Nobody, ever.

Dennis le pregunta si se refiere a lo que siente por Leigh y Arnie le espeta riéndose: «What?, fuck, no. I'm talking about Christine, man!». El joven invade el carril contrario obligando a otro coche a desviarse (le grita "Chickenshit!») ${ }^{74}$, y confiesa: «Oh, man there is nothing finer than being behind of your own car... except maybe for pussy» (versión actualizada de las palabras de George LeBay el día de su primer encuentro con Christine) ${ }^{75}$.

El hecho de que Christine llevase los cristales oscurecidos durante los asesinatos de los miembros de la banda de Repperton le había servido anteriormente a Carpenter para sembrar la ambigüedad sobre si el coche reiniciaba su carrera cri-

${ }^{74}$ Este momento recuerda a los retos propios de la subcultura juvenil de los 50, como el desafío del acantilado en Rebel Without a Cause.

75 Aunque el envilecimiento de Arnie se dota de muchos más matices en la novela (el personaje fuma y trafica con tabaco, alcohol y cocaína para Darnell, llegando incluso a ser detenido), este episodio de la conducción temeraria no aparece en ella. En la obra de King los dos amigos pasan la noche en casa de Arnie y beben juntos, luego Arnie lleva a Dennis a su casa y durante el trayecto éste ve en el espejo retrovisor, una tras otra, a todas las víctimas de Christine, mientras Arnie (que sigue bebiendo) se transforma, por momentos, en Roland LeBay (Cfr. capítulo 45: «New Year’s Eve»). 
minal solo o contaba con la colaboración de Arnie (vestigio de la estructura whodunit generadora de suspense característica de muchos slasher a partir de Friday the 13th). Ahora, sin embargo, es el joven adolescente el que convierte su vehículo en un arma al conducir bebido (recuérdense las palabras de Reagan), además de aceptar de forma explícita los asesinatos de Christine. Esta nueva condición de Arnie se confirma durante el enfrentamiento final en el taller de Darnell: inicialmente reaparece la ambigüedad porque Christine tiene nuevamente los cristales oscurecidos, pero luego vemos a su propietario al volante ${ }^{76}$, pálido y con ojeras (como drogado o borracho), que terminará muriendo tras salir despedido a través del parabrisas. Un final trágico para alguien que se dejó controlar por su automóvil.

ReCibido: mayo de 2020; ACEPTADO: junio de 2020

${ }^{76}$ Antes ya hemos escuchado su voz, que grita «You shitters!», cuando Dennis protege a Leigh con la pala de la excavadora, funcionando, en ese momento, como la voz de Christine. 
